\title{
Complexity in water and carbon dioxide fluxes following rain pulses in an African savanna
}

\author{
Christopher Alan Williams • Niall Hanan · \\ Robert J. Scholes · Werner Kutsch
}

Received: 24 July 2007/Accepted: 16 June 2009/Published online: 7 July 2009

(C) Springer-Verlag 2009

\begin{abstract}
The idea that many processes in arid and semiarid ecosystems are dormant until activated by a pulse of rainfall, and then decay from a maximum rate as the soil dries, is widely used as a conceptual and mathematical model, but has rarely been evaluated with data. This paper examines soil water, evapotranspiration (ET), and net ecosystem $\mathrm{CO}_{2}$ exchange measured for 5 years at an eddy covariance tower sited in an Acacia-Combretum savanna near Skukuza in the Kruger National Park, South Africa. The analysis characterizes ecosystem flux responses to discrete rain events and evaluates the skill of increasingly complex "pulse models". Rainfall pulses exert strong control over ecosystem-scale water and $\mathrm{CO}_{2}$ fluxes at this
\end{abstract}

Communicated by Jim Ehleringer.

Electronic supplementary material The online version of this article (doi:10.1007/s00442-009-1405-y) contains supplementary material, which is available to authorized users.

\author{
C. A. Williams $(\bowtie)$ \\ Graduate School of Geography, Clark University, \\ 950 Main Street, Worcester, MA 01610, USA \\ e-mail: cwilliams@clarku.edu \\ N. Hanan \\ Natural Resource Ecology Laboratory, Colorado State \\ University, Fort Collins, CO 80523-1499, USA \\ e-mail: niall@nrel.colostate.edu \\ R. J. Scholes \\ Council for Scientific and Industrial Research, \\ Pretoria 0001, South Africa \\ e-mail: bscholes@csir.co.za \\ W. Kutsch \\ Max-Planck-Institute for Biogeochemistry, \\ P.O. Box 1001 64, 07701 Jena, Germany \\ e-mail: wkutsch@bgc-jena.mpg.de
}

site, but the simplest pulse models do a poor job of characterizing the dynamics of the response. Successful models need to include the time lag between the wetting event and the process peak, which differ for evaporation, photosynthesis and respiration. Adding further complexity, the time lag depends on the prior duration and degree of water stress. ET response is well characterized by a linear function of potential ET and a logistic function of profile-total soil water content, with remaining seasonal variation correlating with vegetation phenological dynamics (leaf area). A 1- to 3-day lag to maximal ET following wetting is a source of hysteresis in the ET response to soil water. Respiration responds to wetting within days, while photosynthesis takes a week or longer to reach its peak if the rainfall was preceded by a long dry spell. Both processes exhibit nonlinear functional responses that vary seasonally. We conclude that a more mechanistic approach than simple pulse modeling is needed to represent daily ecosystem C processes in semiarid savannas.

Keywords Evapotranspiration .

Net ecosystem carbon exchange - Pulse response .

Soil water dynamics $\cdot$ Ecosystem modeling

\section{Introduction}

About half of global lands experience rainfall in deficit of evaporative demand at timescales from weeks to years (e.g., Slaymaker and Spencer 1998). In these water-limited systems, pulses of rain excite ecosystem dynamics such as microbial decomposition, germination and growth of plants, predator outbreaks and community succession (Schwinning and Sala 2004), with intervening periods of relative inactivity. Ecosystem water use, productivity, and respiration all 
respond to the episodic availability of water (Austin et al. 2004; Baldocchi et al. 2006; Huxman et al. 2004; Jenerette et al. 2008; Porporato et al. 2001; Rodriguez-Iturbe et al. 1999; Xu et al. 2004). This has led dryland ecologists to propose various conceptual and mathematical models to describe ecosystem functional responses to pulses of rainfall or soil water (Schwinning et al. 2004). The pulsereserve paradigm of Noy-Meir (1973), recently modified by Reynolds et al. (2004), and threshold-delay model of Ogle and Reynolds (2004) elaborated by Collins et al. (2008), span the earliest and most recent conceptual models proposed to represent ecological pulse responses. These conceptual descriptions of general system behavior tend not to be tested with data. It therefore remains to be seen if the pulse modeling paradigm is useful in the prediction of ecosystem water and $\mathrm{C}$ fluxes.

The pulse paradigm has promoted a focus on the roles of thresholds and lags in ecosystem dynamics (Schwinning et al. 2004). For example, evapotranspiration (ET) and net ecosystem $\mathrm{CO}_{2}$ exchange are both stimulated by rainfall pulses (Gutierrez and Whitford 1978; Huxman et al. 2004; Knapp et al. 2002; Knapp and Smith 2001; Webb et al. 1978; Williams and Albertson 2004), but the degree, duration and timing of stimulation may be highly variable. While rapid responses to even small wetting events can occur (Fravolini et al. 2005; Sala and Lauenroth 1982), in other cases water and $\mathrm{C}$ fluxes exhibit a delayed response of several days associated with upregulation (physiological recovery from the preceding dry period), and this may reduce the impact of small pulses or reduce sensitivity during certain times of year (Baldocchi et al. 2006; BassiriRad et al. 1999; Schwinning and Sala 2004; Schwinning et al. 2003). Such nonlinear behavior has typically been evaluated using only a few wetting events and would benefit from more extensive quantitative assessment.

If ecosystem responses to rainfall are strongly dependent on when in the year they occur (seasonality) or antecedent vegetation and soil conditions, the simplest versions of the pulse paradigm may not be adequate for predictive modeling. "Path dependency" (i.e., a sensitivity to history), typical of highly seasonal environments (e.g., Scholes and Walker 1993) or those undergoing functional or structural transition (e.g., Briggs et al. 2005), adds complication to the model. Part of the within-pulse and seasonal pattern of water and $\mathrm{CO}_{2}$ fluxes can be clearly attributed to direct effects of time-variation in environmental conditions (Baldocchi et al. 2004; e.g., Falge et al. 2002; Hui et al. 2003; Reichstein et al. 2002). Additional variability can be introduced by transience in functional responses to environmental conditions (Hui et al. 2003). For example, seasonal variation in temperature dependence of ecosystem respiration is often partially explained by coincident soil water status (Reichstein et al. 2002; Tang and Baldocchi
2005; Tang et al. 2005; Xu and Baldocchi 2004) but even this interaction fails to explain the particularly large $\mathrm{CO}_{2}$ releases sometimes observed after even small wetting events following prolonged dry periods (e.g., Jarvis et al. 2007; Jenerette et al. 2008; Xu and Baldocchi 2004). The work of Ogle and Reynolds (2002) illustrates another timevarying functional response with Larrea, whose success in the face of drought may be enhanced by seasonal acclimation of stomatal response to plant water status with growing season temperature. Such functional adjustments are a challenge to model using simplified pulse-response approaches. This leads us to investigate in this paper the degree of variation of water and $\mathrm{CO}_{2}$ flux responses to soil water pulses in a semi-arid savanna, and how much of that variation is captured by models of increasing complexity.

We address the following hypotheses:

1. Soil water pulses stimulate ET, productivity, and respiration processes, with a general decline in activity during the ensuing dry-down (hypothesis 1).

2. The time lag between the increase in soil water and the peak of activity varies between these three (i.e., ET, productivity, and respiration) processes (hypothesis 2).

3. The magnitude of the peak, and lag time to peak, both increase with the intensity of ecosystem dryness prior to re-wetting (hypothesis 3). This stems from a general expectation of the need for upregulation of ecosystem physiological activity following dryness-induced dormancy, akin to the "Birch effect" discussed below.

4. As a consequence of the above factors, a timeinvariant pulse-response model with a fixed characteristic shape misses modulation by seasonal phenology and antecedent wetness, and thus represents daily fluxes poorly (hypothesis 4).

To address these hypotheses we analyze time series of soil water, ET, and net ecosystem $\mathrm{CO}_{2}$ exchange (partitioned into production and respiration) measured over 5 years in an Acacia-Combretum savanna in South Africa. Our analysis assesses the degree to which coincident weather and surface states control ecosystem flux responses to discrete rainfall events. It begins by documenting the average response of $\mathrm{C}$ and water fluxes to soil water pulses. Then, using a 5-month case study which contains three main pulse events, we show such responses to be timevariant and nonlinear. We quantify lags in the response of water and $\mathrm{CO}_{2}$ fluxes to wetting, and then test the ability of alternate "pulse models" of increasing complexity to capture lagged ecosystem responses. The discussion explores minimum parameterization of ecosystem flux responses to soil water pulses, comments on the implications of our findings for the pulse paradigm, and outlines specific challenges that remain in representing complex, transient ecosystem responses to pulses. 


\section{Materials and methods}

Site characteristics

The flux and state observations analyzed in this study were taken between April 2000 and August 2004 at a site $15 \mathrm{~km}$ south west of Skukuza, South Africa. The Skukuza site is $370 \mathrm{~m}$ a.s.1, receives $550 \pm 160 \mathrm{~mm}$ of rainfall annually, with about 65 rainy days per year almost entirely between November and April. The year is divided into a hot, occasionally wet growing season and a warm, dry nongrowing season (Fig. 1).

The shallow coarse sand to sandy loam soils (about $65 \%$ sand, 30\% clay, and 5\% silt) overlay granite, which outcrops in places (Biggs et al. 2003; Sankaran et al. 2004). The landscape is gently undulating, with broad-leaved savanna on the crests dominated by the small tree Combretum apiculatum, and fine-leaved savanna in the valleys dominated by Acacia nigrescens (Scholes et al. 1999). Within the $300 \times 300-\mathrm{m}$ square centered on the tower, tree cover is about $28 \%$ and evenly mixed between Combretum and Acacia. Woody plant basal area is $7 \mathrm{~m}^{2} \mathrm{ha}^{-1}$ (Scholes et al. 1999). Tree canopies average 5-8 m high with
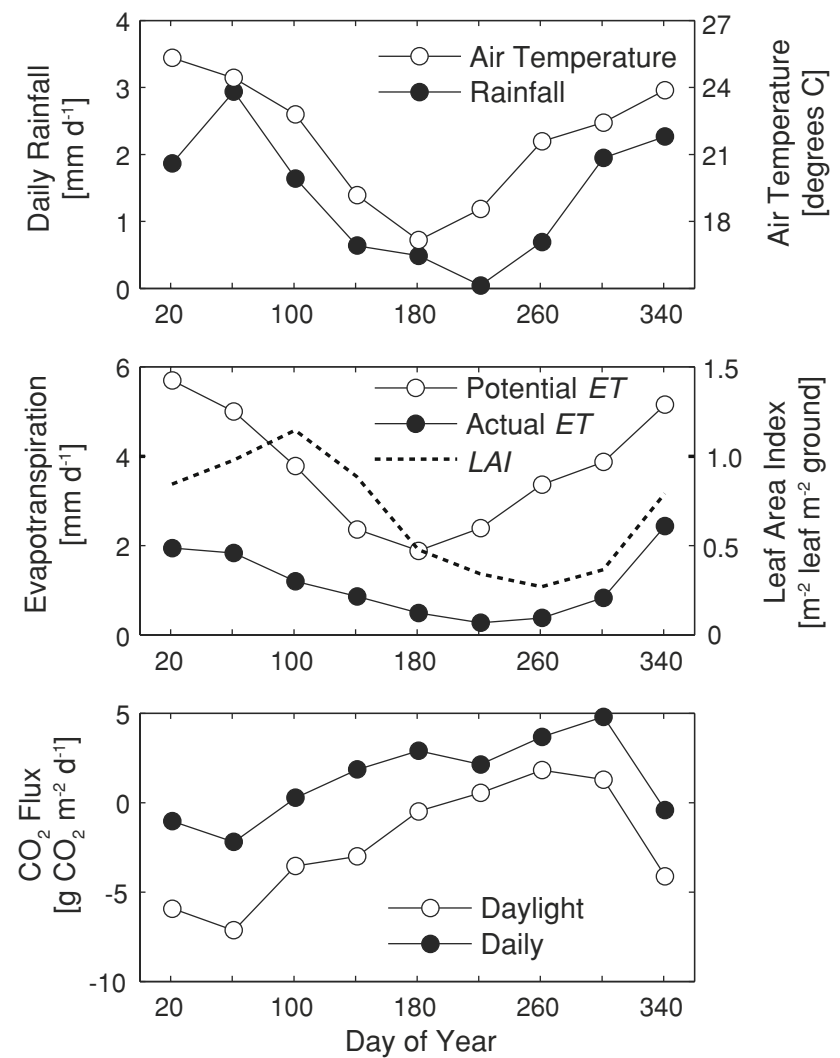

Fig. 1 Mean seasonality of environmental states and fluxes at the Skukuza site, averaged for observations within 40-day windows over years 2000-2004. LAI Leaf area index, ET evapotranspiration, $d^{-1}$ day $^{-1}$ occasional trees (mostly Sclerocarya birrea) reaching $10 \mathrm{~m}$. The grassy and herbaceous understory contains Panicum maximum, Digitaria eriantha, Eragrostis rigidor, and Pogonarthria squarrosa among others. The tree and herbaceous vegetation both root throughout the $\sim 0.6$-m-deep soils.

Leaf area index (LAI; $\mathrm{m}^{2}$ leaf $\mathrm{m}^{-2}$ ground) from 2000 to 2004 was obtained from MODIS LAI cutouts centered over the Skukuza site, made available through the Oak Ridge National Laboratory Distributed Active Archive Center and recalibrated $\left(\mathrm{LAI}_{\text {field }}=0.5 \mathrm{LAI}_{\text {MODIS }}\right)$ against in situ observations made on multiple occasions with a Decagon Accupar ceptometer (Pullman, Wash.) at 49 systematically sampled locations within $150 \mathrm{~m}$ of the tower. Growing season LAI averaged about 1.1 (Fig. 1) during the period of flux tower observations reported here, but has reached as high as 2.0 for the more extended MODIS LAI record.

Measurements and data processing

A 22-m tower was instrumented at $16 \mathrm{~m}$ with a sonic anemometer (Gill Instruments Solent R3, Hampshire, England) measuring three-dimensional, orthogonal components of velocity $\left(u, v, w ; \mathrm{m} \mathrm{s}^{-1}\right)$ as well as the "sonic" air temperature $\left(T_{\mathrm{a}} ;{ }^{\circ} \mathrm{C}\right)$, and a closed-path infrared gas analyzer (IRGA; LiCor 6262; LiCor, Lincoln, Neb.) measuring concentrations of water vapor $\left(q ; \mathrm{mmol} \mathrm{H}_{2} \mathrm{O} \mathrm{mol}^{-1}\right.$ moist air), and $\mathrm{CO}_{2}$ ( $\mu \mathrm{mol} \mathrm{CO} \mathrm{CO}_{2}^{-1}$ air). Manual IRGA calibrations were performed approximately monthly. Calibrations were done in the field using Level-5 (99.999\% pure) $\mathrm{N}$ for $\mathrm{CO}_{2}$ and $\mathrm{H}_{2} \mathrm{O}$ zero (this was also the reference gas running continuously through the reference cell in the 6262). Spans were carried out using National Oceanographic and Atmospheric Administration (NOAA) secondary standard calibration gases calibrated to $<0.2$ p.p.m. for $\mathrm{CO}_{2}$ and a LiCor dew point generator for $\mathrm{H}_{2} \mathrm{O}$. Analytical flux footprint estimation (Gash 1986; Hsieh et al. 2000) indicates that a source area within $130 \mathrm{~m}$ upwind of the tower typically contributes $90 \%$ of the measured flux and a source area within $1.3 \mathrm{~km}$ contributes $99 \%$ of the flux.

Post-processing of the raw high frequency $(10 \mathrm{~Hz})$ data for calculation of above-canopy turbulent fluxes of sensible heat $\left(H ; \mathrm{W} \mathrm{m}{ }^{-2}\right)$, water vapor $\left(\mathrm{LE} ; \mathrm{W} \mathrm{m}{ }^{-2}\right)$, and $\mathrm{CO}_{2}\left(F_{\mathrm{c}}\right.$; $\mathrm{g} \mathrm{CO}_{2} \mathrm{~m}^{-2}$ time $^{-1}$ ) calculated for half-hour periods is consistent with methods advised in Lee et al. (2004), and involved standard spike filtering, planar rotation of velocities applied to monthly data for $60^{\circ}$ sectors (Wilczak et al. 2001), as well as lag correction to $\mathrm{CO}_{2}$ and $q$ from analysis of monthly peaks in lagged cross-correlations of vertical velocity and scalars. Heat and mass fluxes were calculated with conventional equations (see e.g., Aubinet et al. 2000; 
Moncrieff et al. 1997). All fluxes are reported as positive upward from the land to the atmosphere. Frequency response correction of some of the energy lost due to instrument separation, tube attenuation, and gas analyzer response for LE and $F_{\mathrm{c}}$ was performed with empirical cospectral adjustment to match the $H$ cospectrum (Eugster and Senn 1995; Su et al. 2004).

Canopy storage flux was estimated from the half-hourly time derivative of a 16-m-column integral based on $\mathrm{CO}_{2}$ concentrations measured with PP Systems (Amesbury, Mass.) CIRAS-SC infrared gas analyzers in two separate profiles $40 \mathrm{~m}$ on either side of the main tower, with air intake at heights of $0.75,2.0,3.5$, and $5.25 \mathrm{~m}$, plus the $16-\mathrm{m}$ concentration on the main tower, and added to the above-canopy turbulent flux for data analysis. Average half-hourly incoming and outgoing longwave and shortwave radiation was measured with a Kipp and Zonen (Delft, The Netherlands) CNR1 radiometer mounted at $22 \mathrm{~m}$, the balance of which provides net radiation $\left(R_{n} ; \mathrm{W} \mathrm{m}{ }^{-2}\right)$.

Average half-hourly volumetric soil water content $(\theta$; $\mathrm{m}^{3} \mathrm{H}_{2} \mathrm{O} \mathrm{m}^{-3}$ soil) was estimated with 15 -cm-long Campbell Scientific (Logan, Utah) frequency domain reflectometry probes (CS615) installed horizontally in four separate profiles, two in the Acacia-dominated [probes at soil depths $(z, \mathrm{~cm})$ of $3,7,16,30$, and $50 \mathrm{~cm}]$ and two in a Combretum-dominated area (probes at 5, 13, 29, and $61 \mathrm{~cm}$ ). The probes have not been locally calibrated, and while manufacturer notes suggest absolute accuracy to within $2 \%$, our estimates of soil water content are approximate, still providing a robust measure of the relative moisture dynamics. Half-hourly averaged soil heat flux $\left(G, \mathrm{~W} \mathrm{~m}^{-2}\right.$ ) was obtained with HFT3 plates (Campbell Scientific) installed $5 \mathrm{~cm}$ below the ground both under and between tree canopies. Rainfall per half-hour was measured with a tipping bucket rain gage (TE525-L; Campbell Scientific) located on the tower top.

Above-canopy vapor pressure deficit was calculated as the difference between the saturation vapor pressure at $T_{\mathrm{a}}$ and near surface atmospheric pressure $\left(P_{\mathrm{a}}\right.$; recorded at a nearby weather station), and the atmospheric water vapor pressure obtained from $q$ and $P_{\mathrm{a}}$. Total root zone soil water $(S ; \mathrm{cm})$ was calculated as the sum of $S_{i}$, where

$S_{i}=\left\{\begin{array}{ll}\theta_{1}\left[\left(z_{2}-z_{1}\right) / 2+z_{1}\right] & \text { for } i=1 \\ \theta_{i}\left(z_{i+1}-z_{i-1}\right) / 2 & \text { for } 1<i<N \\ \theta_{N}\left[65-\left(\left(z_{N}-z_{N-1}\right) / 2+z_{N-1}\right)\right] & \text { for } i=N\end{array}\right\}$

and where $N$ is the number of measurement depths. While we considered a root zone weighting of soil moisture for use in analyses of canopy ecophysiology, we proceeded with this bucket approach given that all the plant functional types present in the tower's footprint root throughout the profile. Daily potential ET rate (PET; $\mathrm{mm} \mathrm{day}^{-1}$ ) is estimated with the Priestley and Taylor (1972) formulation

$\mathrm{PET}=\sum_{i=1}^{48}\left[\alpha\left(R_{n i}-G_{i}\right) \frac{\Delta}{\Delta+\gamma}\right] \frac{\tau}{L_{v}}$,

where $\alpha(=1.26)$ accounts for large-scale advection and entrainment, $\gamma\left(=0.67 \mathrm{mb}{ }^{\circ} \mathrm{C}^{-1}\right)$ is the psychrometric constant, $L_{v}\left(=2.45 \times 10^{6} \mathrm{~J} \mathrm{~kg}^{-1}\right)$ is the latent heat of vaporization, $\Delta\left(\mathrm{mb}^{\circ} \mathrm{C}^{-1}\right)$ is the slope of the saturation vapor pressure curve (Campbell and Norman 1998), and $\tau$ $(=1,800)$ is the number of seconds per half hour. Total daily ET $\left(\mathrm{mm} \mathrm{day}^{-1}\right)$ is calculated from LE, $L_{v}$ and $\tau$. Energy balance closure, $(H+\mathrm{LE}) /\left(R_{n}-G\right)$, averages $74 \%$ for half-hourly data and $86 \pm 17 \%$ for the daily time scale.

$\mathrm{C}$ fluxes are also represented as temporal sums over daily ( $24 \mathrm{~h}$ ), daytime ( $12 \mathrm{~h}$ from 0800 to 2000 hours), and nighttime ( $8 \mathrm{~h}$ from 2200 to 0600 hours) of the day. Data were only included in the summation if friction velocity exceeded $0.1 \mathrm{~m} \mathrm{~s}^{-1}$, a widely used threshold for valid eddy covariance measurements (Baldocchi 2003). In addition, a 15-day mean diurnal replacement as in Falge et al. (2001) was applied to fill missing values for daytime, nighttime and daily summations. Summations of gap-filled data were included in analyses only if fewer than $10 \%$ of the data had been filled by this procedure.

\section{Analyses}

The average temporal dynamics of fluxes responding to significant soil wetting events $(\geq+5 \mathrm{~mm}$ soil water) are calculated for dry and wet season populations during the period April 2000 to July 2004. Here, observations were only included for a lag of one up to $n$ days if a second soil wetting $(S \geq 5 \mathrm{~mm})$ did not occur during the period. Neither the mean depth of a rainfall event nor the postpulse accumulated rainfall differs between the dry and wet populations; the key difference is the gap between rainfall events. Functional control of fluxes by root-zone soil water was also examined with averages for data during the growing season. In both the temporal and functional analyses we investigate the presence of lags to peak response.

To more directly assess dynamics of the main $\mathrm{C}$ exchange processes we apply a simple approach to separating the net flux $\left(F_{\mathrm{c}}\right)$ into respiration and production components. Respiration is estimated by scaling mean nighttime $\mathrm{CO}_{2}$ flux to a 24-h total, then subtracting this from total daily $\mathrm{CO}_{2}$ flux to obtain an estimate of daily photosynthetic productivity. Temperature variations during the summer growing seasons at this site do not include extreme low or high temperatures that severely limit plant 
or microbial physiology. Lacking clear relationships between nighttime $\mathrm{CO}_{2}$ flux and air or soil temperature, it was not appropriate to include temperature as an independent variable in the estimation of daily respiration based on nighttime $\mathrm{CO}_{2}$ flux despite its conventional appeal.

Time-dependency of water and $\mathrm{C}$ flux responses is examined with a case study from a 5-month period of 2003, illustrating lags and their association with time-varying environmental conditions. Then, to move toward predictive understanding of the observed lags and peaks, we evaluate two metrics of the recent history of water status in terms of their skill in predicting the lags of respiration and productivity. The first is simply an average of the $x$-day history of soil water content $\left(S_{x}\right)$. The second is an index of water deficit days $\left(\mathrm{WDD}_{x}\right)$, defined as the cumulative sum of daily soil water deficits since the last time [ $T$ (days) with a max of $x$ days] soil water dropped below a threshold $(7 \mathrm{~cm})$ level below which $\mathrm{H}_{2} \mathrm{O}$ and $\mathrm{CO}_{2}$ fluxes transition into a water-limited state at this site (evidenced in the results), and formally

$\mathrm{WDD}_{x}=\sum_{t=1}^{T} 7-S_{t}$,

where $t=1$ to $T$ days prior and $T$ cannot exceed $x$ days prior. The two metrics are negatively, linearly related below the threshold and unrelated above it. They are alternate means of representing a similar phenomenon. Only ten events contained the necessary data for inclusion in this analysis, which requires a rain event followed by rain-free conditions and gapless daily fluxes for at least as long as the 10-day lag period, and a pre-pulse record of at least as long as the relevant WDD history.

The final analyses involve a "model intercomparison", evaluating data support from the full measurement record for empirical models of daily water and $\mathrm{C}$ processes that vary in complexity. We used the simplest possible representation of a pulse response - a "square wave" in which ET/PET, respiration, and productivity are assigned a constant high value where $S$ is greater than $5 \mathrm{~cm}$, and a low value if not-as a reference point, and then added progressive refinements. Rather than imposing a particular functional form to these more complicated models a priori, base models were first selected from regression fits of a wide range of linear and nonlinear models using the CurveFinder function of the program CurveExpert 1.3. From this analysis we found that linear and logistic models tended to provide the best functional descriptions without an excessive number of parameters. We then explored linear and logistic dependence of ET/PET, respiration, and productivity each on: (1) day of year as a purely seasonal model, (2) 0- to 30-day average rainfall, (3) 0- to 20-day average $S$, and (4) 0- to 100-day WDD histories (Eq. 3). As a third step in model testing, we performed a linear regression of the residuals on LAI (linearly interpolated to a daily series). Full details of the model exercise can be found in the Electronic Supplementary Material.

\section{Results}

Pulse responses

Figure 2 shows the characteristic flux responses of ET, net ecosystem exchange, and respiration to rainfall pulses and associated soil wetting events ( $\geq+0.5 \mathrm{~cm}$ soil water). Soil water declines monotonically following wetting events, with an average decline of $40 \%$ between the peak and 30 days after wetting. ET and respiration (inferred from nighttime $F_{\mathrm{c}}$ ) are both rapidly stimulated, with an initial increase to their maxima that lags 1-4 days after rainfall, followed by a general (though variable) decay. For ET, dry and wet season responses differ according to an analysis of covariance (ANCOVA) grouping by dry or wet season and testing covariation with time since wetting, which yielded a non-significant interaction (season $\times$ time $P=0.7497$ ) but significant dependence on both season $(P<0.0001$, $d f=207)$ and time $(P=0.0004, d f=207)$. The dry season pulse response of ET is lower and also slightly delayed because of the drier initial condition but reaches a similar peak to that achieved in the wet season. In contrast, the response of respiration to wetting did not differ between seasons (ANCOVA season $\times$ time $P=0.2644$, season $P=0.351$, time $P<0.0001$ with $d f=257$ ), though the daily net ecosystem exchange response did (ANCOVA season $\times$ time $P=0.0186$, season $P<0.0001$, time $P=0.004, d f=255)$.

The rapid response of respiration to soil wetting dominates the daily total net $\mathrm{C}$ exchange $\left(F_{\mathrm{c}}\right)$ during the first 3 days after rainfall, suggesting that upregulation of productivity in response to the moisture pulse is delayed. This interpretation is supported by the continued net release of $\mathrm{CO}_{2}$ for the dry season population, in contrast to the switch to net ecosystem $\mathrm{C}$ uptake (negative $F_{\mathrm{c}}$ ) in the wet season, peaking on average about 9 days after wetting. A wide spread about the average for each functional response indicates that a single characteristic response irrespective of the degree of wetting, prevailing environment, or antecedent conditions provides a poor system description even when seasonally stratified. The fit is poorest for daily $F_{\mathrm{c}}$.

An alternative to constructing the "characteristic" pulse trajectories shown in Fig. 2 is a functional response to soil moisture, independent of time, as shown in Fig. 3. While there is considerable variability around these average functional responses, the broad patterns are clear. ET, when 

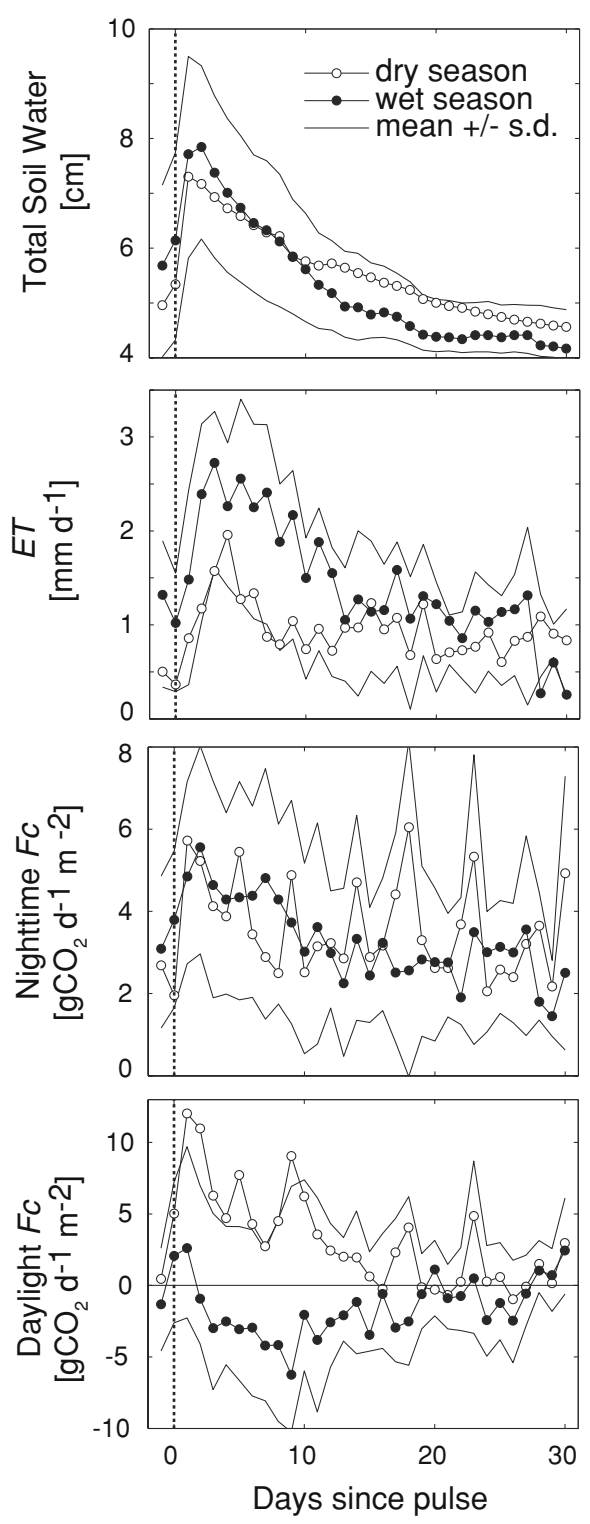

Fig. 2 Average (bold line) soil moisture, daily evapotranspiration, nighttime $\mathrm{CO}_{2}$ flux, and daytime $\mathrm{CO}_{2}$ flux following rainfall pulses averaged across 53 events of varying event size and preceding rainfree duration during the 2000-2004 observation period. Data are pooled into dry season (open symbols) and wet season (closed symbols). Thin lines represent \pm 1 SE about the mean across dry and wet seasons combined for visual clarity

expressed relative to PET, is well predicted by a logistic function of total root zone water content $(\mathrm{cm})$ : ET/ PET $=0.59 /[1+4,170 \exp (-1.78 S)]$, with a SE of regression $=0.11, \quad$ coefficient of determination $\left(R^{2}\right)=0.70$, and $P$-value $<0.001$. Nighttime $\mathrm{CO}_{2}$ flux (i.e., respiration) shows a remarkably similar positive relationship with total root zone water content \{respiration $\left(\mathrm{g} \quad \mathrm{CO}_{2} \quad \mathrm{~m}^{-2} \mathrm{day}^{-1}\right)=5.5 /[1+269 \exp (-1.15 S)]$; $\left.R^{2}=0.36, P<0.001\right\}$ These relatively simple log-linear
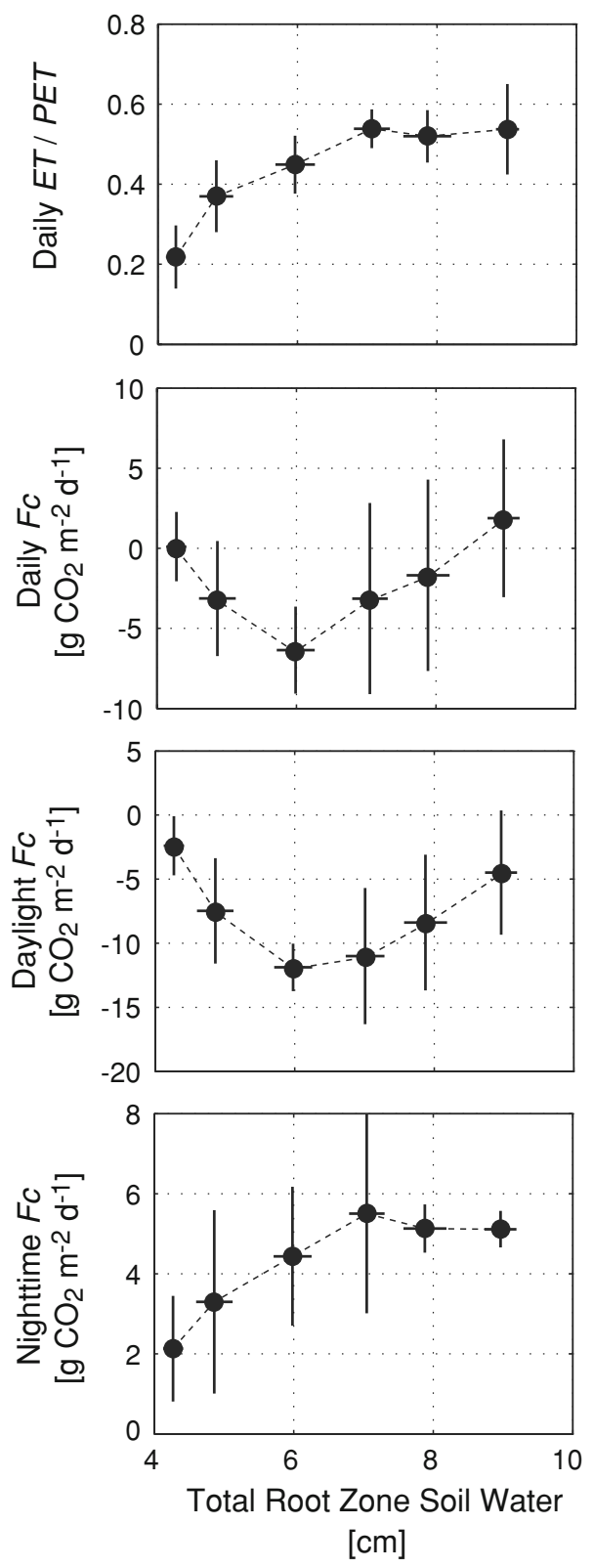

Fig. 3 Growing season (December-March, 2000-2004) average functional responses of $\mathrm{CO}_{2}$ fluxes and ET to profile soil water content. One SD ranges shown with solid vertical and horizontal lines

functional responses to soil water content are consistent with the short lag times for these processes.

In contrast, responses of both daytime (12 h) and daily $(24 \mathrm{~h})$ net ecosystem exchange are more complex, since they include the longer lag inferred for photosynthetic upregulation. $\mathrm{CO}_{2}$ exchange during daylight hours shows an apparent minimum (i.e., maximum uptake given that downward fluxes are negative) at intermediate rather than high soil water content, because the rapid decline in soil moisture in the days after wetting, coupled with a photosynthetic response lagged by up to a week, tends to obscure 
the expected monotonic relation between soil moisture and net ecosystem exchange. Similarly, net 24-h $\mathrm{CO}_{2}$ flux is apparently near zero at high soil water content, reaches a minimum at intermediate soil water content, and is near zero again when the soil is dry.

To examine the time dependency of these patterns, we turn to a case study from a 5-month period during 2003 (Fig. 4) extending from the peak of the wet season (February) through the early dry season (June). The LAI declined from about 0.7 to 0.4 during this period (linear regression, $P=0.082$ ). The three largest daily rainfall pulses were 54,36 , and $37 \mathrm{~mm}$ (the third pulse spanning 2 days). Soil water content is seen to exert strong control on water and $\mathrm{CO}_{2}$ fluxes, with ET increasing, and $F_{\mathrm{c}}$ initially rising to a positive peak, then switching to negative values peaking after about a week, then returning gradually to close to zero. However, comparison of flux responses between major wetting events shows that soil water is only one of a suite of environmental controls governing ET and $F_{\text {c }}$. Despite 1.3 times more water initially available in the first event [day-of-year (DOY) 23] relative to the second (DOY 63), peak ET was nearly identical. Furthermore, minimum $F_{\mathrm{c}}$ was about 2 times lower for the second event, with about $5 \mathrm{~g} \mathrm{CO}_{2} \mathrm{~m}^{-2}$ day $^{-1}$ more $\mathrm{CO}_{2}$ uptake for the DOY 63 event than the DOY 23 event after a lag of 8 days. Considering that net ecosystem $\mathrm{CO}_{2}$ exchange is the difference between respiration and production, it could be inferred that respiration declines more rapidly for the event with lower soil water content (as in Fig. 3) or alternatively that production exhibits an acclimation to prior wetting, with a higher maximal productivity for an ecosystem already upregulated by recent wetting.
Comparing the second and third major wetting events (DOY 63 and 117), peak total root zone soil water is nearly equal (Fig. 4). However, soil water declines more rapidly in the second compared to the third wetting event, corresponding with a peak ET that is 1.7 times higher in the former. This is largely explained by the relatively low PET at the time of the third compared to second wetting event: note that the magnitude of ET/PET is similar in both cases (Fig. 4). However, this cannot explain the large difference in net $\mathrm{C}$ flux between the second and third events. Net $\mathrm{C}$ flux for each day after wetting is about $10 \mathrm{~g} \quad \mathrm{CO}_{2}$ $\mathrm{m}^{-2}$ day ${ }^{-1}$ higher (more positive) for the third than second event. The difference is likely due to the respiration term remaining high but photosynthesis being reduced due to leaf senescence and abscission. Die-off of the herbaceous vegetation typically starts at the end of April in this region, while tree leaf fall begins during May if the soil dries out.

Respiration responds more rapidly to wetting than does productivity (Fig. 5), with a 1- to 3-day lag to the maximum respiration response and a 4- to 14-day lag to the maximum productivity response. Nonetheless, despite a relatively long lag to the peak productivity response, productivity begins to increase on the day immediately following soil water pulses (Fig. 5), rising slowly thereafter. In addition, small wetting events (2-10 $\mathrm{mm} \mathrm{day}^{-1}$ of rain), despite leading to only slight increases in total root zone soil water, cause distinct increases in respiratory $\mathrm{C}$ flux but little or no response in productivity (Fig. 5, arrows).

Peaks and lags of ET/PET, productivity, and respiration responses to wetting are not related to the size of rain events triggering pulse responses $(P>0.15)$, and peaks are also unrelated to water stress history $(P>0.25)$. However,
Fig. 4 Time series of soil moisture pulses and associated daily $\left(24 \mathrm{~h}\right.$ ) water and $\mathrm{CO}_{2}$ flux responses spanning day-of-year 18-170 of 2003. Dotted lines provide a visual reference of the maximum responses for various processes contributing to ecosystem fluxes

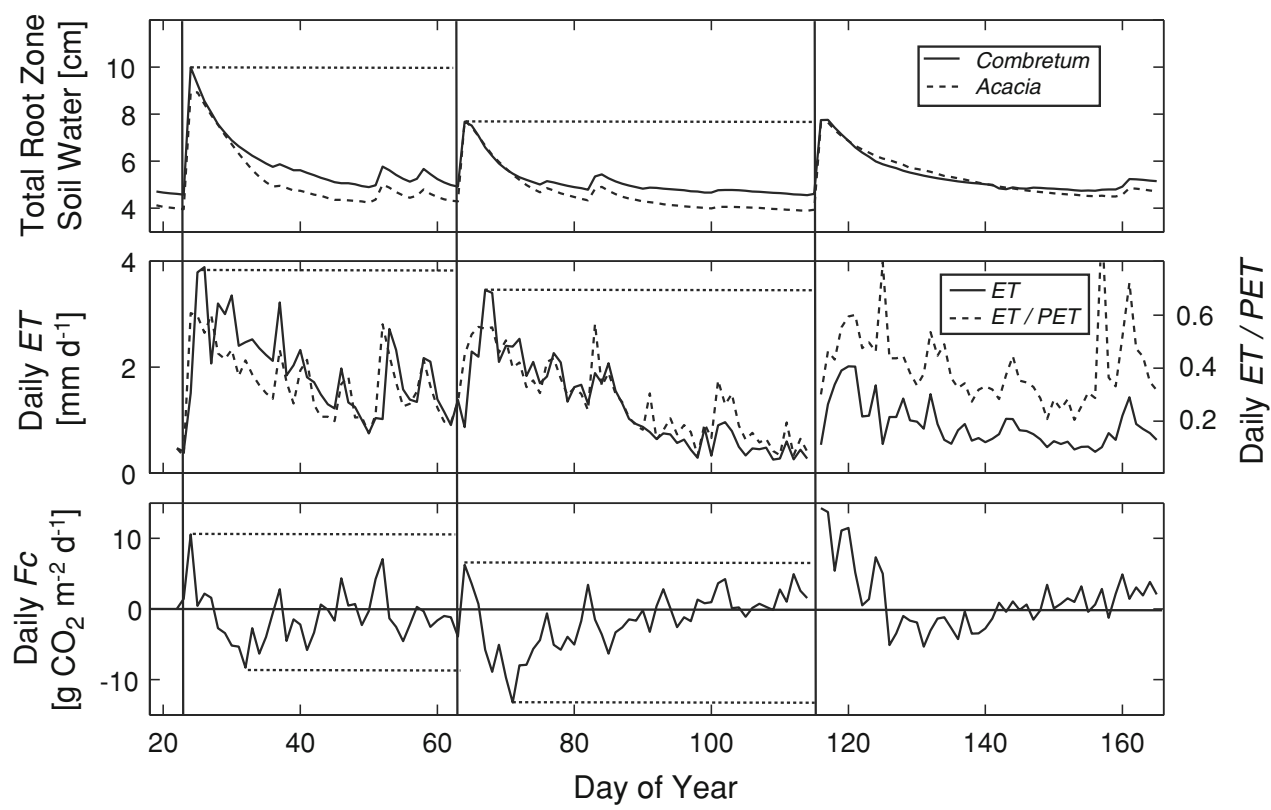




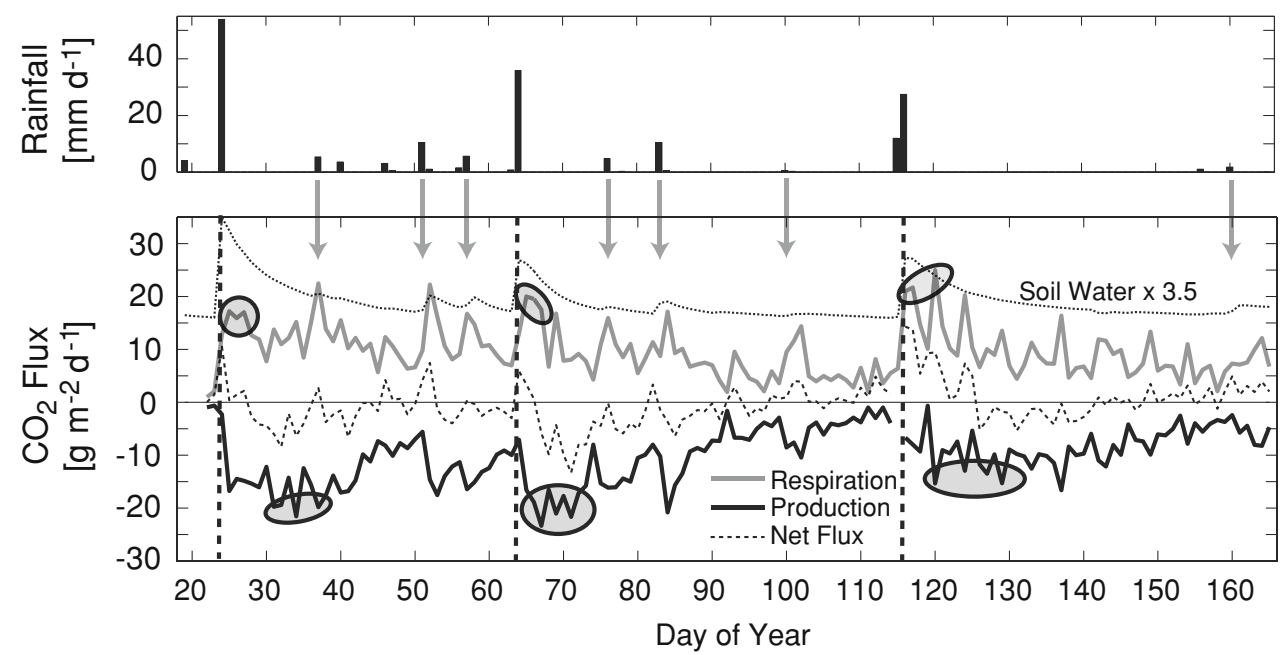

Fig. 5 Daily rainfall (top panel), respiration and production estimates (bottom panel) for a 5-month case study in 2003, where respiration is estimated from measured nighttime $\mathrm{C}$ flux and production is the difference of respiration and 24-h net $\mathrm{C}$ flux. Also shown is total root zone soil water $(\mathrm{cm})$ measured in the Acacia savanna (increased by a factor of 3.5 for clarity). Dashed vertical lines indicate major wetting events. Dashed ellipses highlight maximum production and respiration responses following wetting. Arrows highlight responses to smaller wetting events
Fig. 6 Lag to maximum respiration or productivity response versus the 38-day water deficit days index $\left(W D D_{38}\right)$ and the 10-day average history of total root zone soil water $\left(S_{10}\right)$
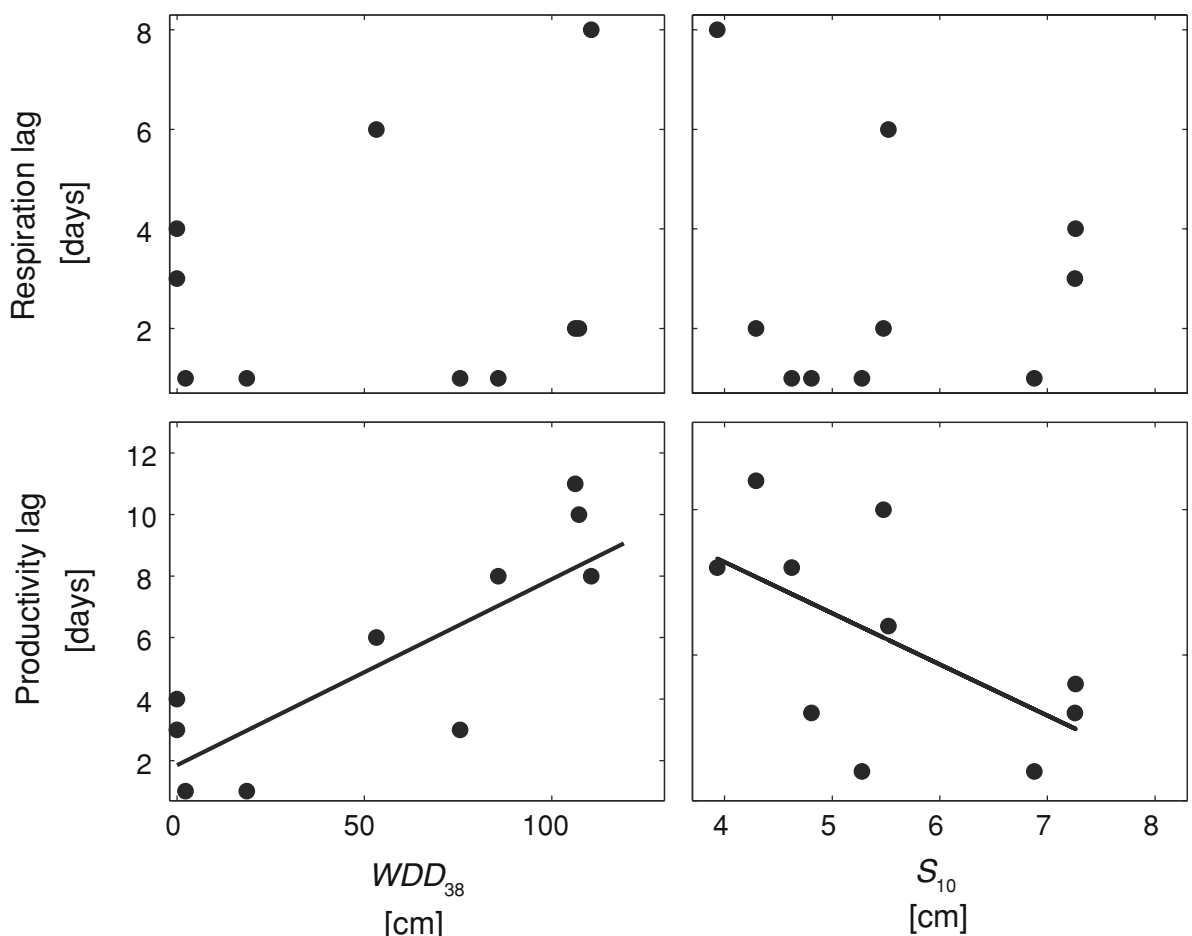

the lag time to peak productivity shows linear dependence on $\mathrm{WDD}_{38}\left(R^{2}=0.72, P=0.002\right)$ and somewhat weaker dependence on $S_{10}\left(R^{2}=0.35, P=0.073\right)$ (Fig. 6). The subtle respiration lag is not predicted by water stress history $(P \geq 0.608)$ (Fig. 6).
Model comparison

Figure 7 presents results of the model comparison, reporting statistics for the water stress index $\left(S_{x}\right.$ or $\left.\mathrm{WDD}_{x}\right)$ that maximized model efficiency where appropriate. 

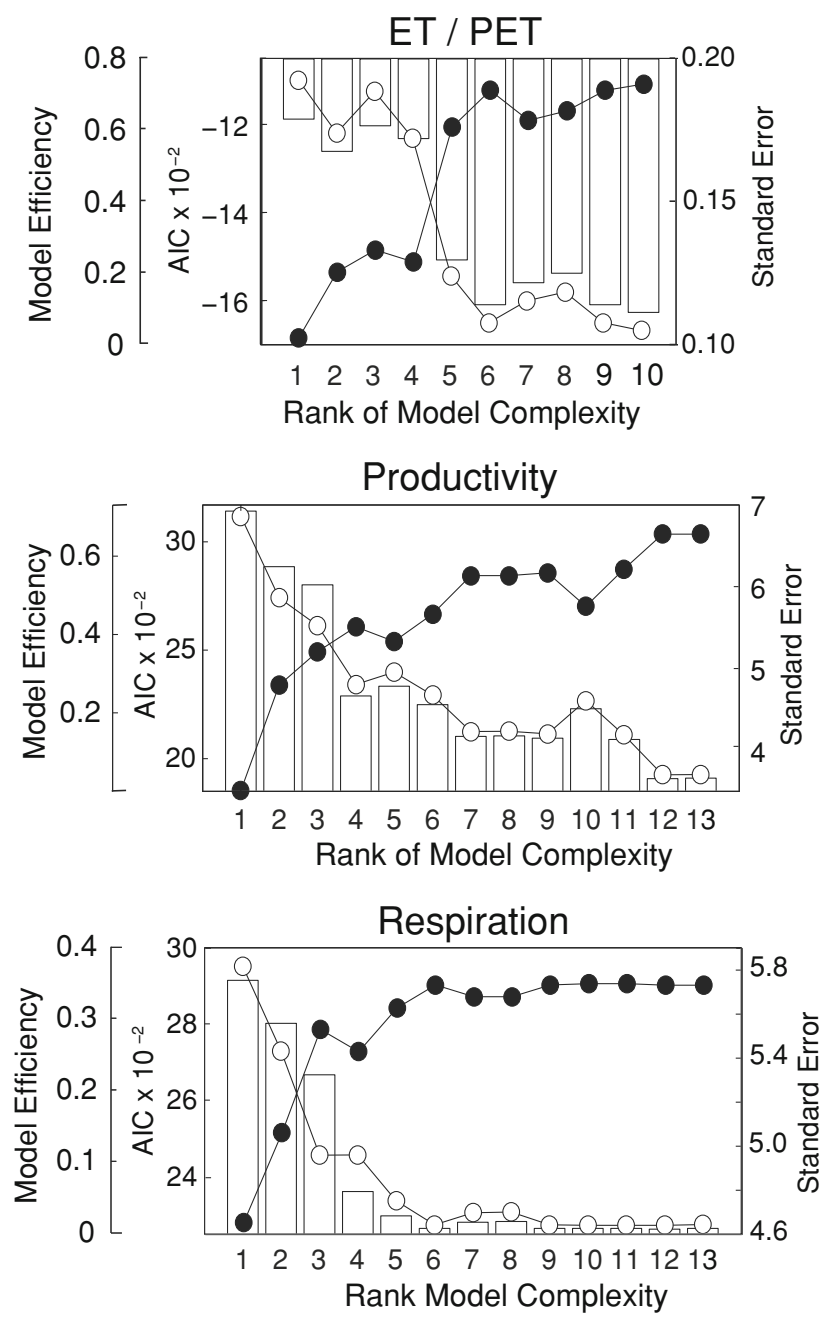

Fig. 7 Statistics of model fitting for ET/potential ET (PET), productivity, and respiration showing Akaike information criterion (AIC; bars), model efficiency or $r^{2}$ (closed circles), and SE of regression (open circles), where numbers on the $x$-axis correspond to the following models: linear regression with daily rainfall (1), linear regression with day of year (offset for water year) (2), square waveconstant values for a low soil moisture or high soil moisture class (3), 30-day moving average rainfall history (4), linear function of daily soil moisture (5), logistic function of daily soil moisture (6), linear function of $\mathrm{x}$-day moving average soil moisture history (7), linear function of $\mathrm{x}$-day moving average soil moisture history with linear function of LAI for residuals (8), logistic function of x-day moving average soil moisture history (9), logistic function of daily soil moisture with linear function of LAI for residuals (10), logistic function of $\mathrm{x}$-day moving average soil moisture history with linear function of LAI for residuals (11), linear function of x-day history for WDD (12), linear function of $\mathrm{x}$-day history for WDD with linear function of LAI for residuals (13). For other abbreviations see Figs. 1 and 6

Overall, the purely seasonal, square wave, and rainfallbased models performed poorly compared to models dependent on soil moisture, though prediction with rainfall alone did improve with increased time averaging from daily to a 30-day history.
For ET/PET, predictive skill is greatly improved from the square wave to a model that includes a linear dependence on soil water content $(S)$, and was further modestly improved by a logistic dependence on $S$. AIC only weakly supported LAI as an additional predictor, accounting for longer term (8 days to several months) variations, explaining only an additional $2 \%$ of the variability in ET/ PET. Remaining variation is partly due to the hysteresis resulting from the lag to maximal ET following wetting. However, a logistic function of soil water history $\left(S_{x}\right)$ decreases the fit relative to simply using the soil water content on the day. Taken together, an equation of the form $\mathrm{ET}=\operatorname{PET} \times[\operatorname{logistic} f$ (soil water) $+\operatorname{linear} f$ (leaf area) $]$ explains $72 \%$ of the variation in daily ET at the savanna site studied in this work.

Respiration is also better described by a logistic function of soil water than a square wave or linear model, but only $36 \%$ of the variance is explained and LAI adds little to no explanatory power. Models of productivity benefited most from added complexity. Including the effect of water stress history (the 15-day average soil moisture, or accumulated water stress days) generally improved the fit to productivity by capturing a short-term "memory" of ecosystem water status and the associated lag in productivity response. Residual dependence of productivity on LAI was poorly supported by information criteria and provides only a marginal increase to the coefficient of determination or reduction to SE of regression.

\section{Discussion}

Results confirm that rainfall events stimulate pulse responses of ET, respiration and productivity at the daily time scale in the savanna under study (hypothesis 1). Only a subtle lag to peak stimulation for ET and respiration, is contrasted by a significant lag to peak for photosynthesis, taking a week or longer to reach its peak and supporting hypothesis 2. Correspondingly, prior dryness was not a predictor of lags in ET or respiration responses; however, intensity and duration of pre-pulse dryness is a valuable predictor of lags in productivity, supporting hypothesis 3 . It is still worth mentioning that a short, 1-3 day, lag to maximal ET following wetting is a mild source of hysteresis in the ET response to soil water even after controlling for PET variation.

The temporal dynamics of NEE reported here, with faster upregulation and ensuing decay for respiration compared to productivity, are consistent with those documented for irrigated grass communities of Arizona (Huxman et al. 2004), as well as a number of conceptual models (e.g., Schwinning et al. 2004). Rapid, punctuated increase in respiration following wetting as reported here is 
common in water-limited systems (Jenerette et al. 2008; Xu and Baldocchi 2004). However, soil wetness accounts for only $36 \%$ of the total variation in respiration observed at the Kruger savanna. Again, pre-pulse dryness is not a significant predictor of respiration dynamics. Temperature dependence of respiration is unclear at the site though results from Kutsch et al. (2008) suggest that it may still account for some of the remaining variation. Perhaps more importantly, some measure of the availability of $\mathrm{C}$ substrate is a sensible candidate, possibly capturing a "Birch effect" (see Jarvis et al. 2007), meaning a burst of microbial decomposition and $\mathrm{N}$ mineralization excited by the rewetting of soils that have been dry for a long period. However, it is not possible to separate autotrophic and heterotrophic respiration from the ecosystem total fluxes alone and thus attribution of pulse respiration to a Birch effect cannot be evaluated here.

Results suggest that an integrated measure of plant water status such as stress history would improve model predictions of productivity. We note, however, that the peak magnitude does not depend on pre-pulse dryness. Thinking about mechanisms, it is not surprising that ecosystem physiological responses to wetting are delayed by prolonged dry spells, particularly in a water-limited system in which vegetation dehydrates and becomes dormant at monthly to seasonal time scales. One might then expect part of the variation in lag to peak productivity to be captured by LAI, so the general lack of residual dependence on LAI may seem surprising. However, this can be explained by the temporal correlation of LAI with $S_{x}$ and $\mathrm{WDD}_{x}$ (the correlations were 0.79 and -0.79 for $x$ equal to 20 days). Thus most of the effect of LAI is already expressed in the water stress index.

\section{Implications for the pulse-reserve paradigm}

The pulse-reserve paradigm, introduced by Noy-Meir (1973), modified by Reynolds et al. (2004), and reconceived as the threshold-delay model by Ogle and Reynolds (2004), purports to describe ecological dynamics based on a very simple principle: there is a characteristic pulse of activity following a wetting event. It is attractive because it reduces the system to a few simple inputs, such as initial resource condition and the time since a pulse. But this study demonstrates that in order to realistically capture the observed behavior of a pulsed system, pulses need detailed parameterization to adjust the generalized unit response function for weather, vegetation, and the recent history of the system (hypothesis 4), and likely for soils and climate. Such parameterizations may be site specific, and thus not suitable for extrapolation in general predictive models.

While the pulse-response approach lends itself to synthetic parameterization of system lags and thresholds such as those documented here for the Skukuza site, our observations suggest that a reduced-form pulse-response model is probably not an appropriate choice for capturing the daily dynamics of net ecosystem $\mathrm{CO}_{2}$ exchange (hypothesis 4). Models that represent the differentially lagged temporal responses of ET, respiration and productivity appear necessary. Thus, while the pulse-response paradigm has value for conceptualizing time-domain variation of ecosystem processes, the approach has few advantages for predicting how water and $\mathrm{C}$ dynamics relate to a changing environment.

\section{Minimum parameterizations}

Nonetheless, suggestions for minimum parameterizations emerge. For example, findings from the Skukuza tower site lend confidence to widely applied space-time models describing the co-evolution of ET and soil water dynamics (e.g., Rodriguez-Iturbe et al. 1999; Williams and Albertson 2005). In such minimum parameterizations, the core system behavior that needs to be carefully prescribed is the daily rate of ET as a function of soil water, with additional adjustment by vegetation fractional cover or leaf area. The daily canopy-scale ET of the heterogeneous savanna studied here is well-characterized by PET, total root zone soil water, and seasonal vegetation dynamics, consistent with Williams and Albertson (2005). While a sub-daily resolution may be important for some applications (i.e., land surface coupling to the atmospheric boundary layer) we find that $72 \%$ of the interstorm to seasonal dynamics are captured at a daily resolution.

Our findings also provide general support for the use of simple ("bucket") soil water models, indicating that the added complexity of multi-layer models that parameterize wetting fronts, root distributions and soil water potential may not always be needed for describing daily to monthly time-scale behavior of the coupled ET and soil water dynamics. However, we note that sites with deeper soils might still require a soil water model and root distribution model with vertical detail, especially where there exists a vertical root niche separation between trees and grasses influencing their relative activity.

Previous work has explored the use of a constant canopyscale water use efficiency to characterize daily net $\mathrm{CO}_{2}$ flux as a function of ET during the growing season (Scanlon and Albertson 2004; Verhoef et al. 1996; Williams et al. 2004) motivated by functional coupling of leaf-scale water and $\mathrm{CO}_{2}$ exchanges combined with similar sensitivity to soil water for productivity and respiration. In this study, the different time scales of the respiration and productivity responses to wetting call that idea into question. We note that the ratio of average monthly $F_{\mathrm{c}}$ to ET is surprisingly conservative during the growing season but different in 
the dry season (not shown but can be loosely inferred from Fig. 1). While the application of seasonally varying parameters could improve fit, a more mechanistic approach would be preferred, possibly by representing temporal dynamics of likely drivers of ecosystem process peak rates, such as labile soil $\mathrm{C}$, or lags, such as vegetation water stress history.

\section{Some challenges}

Space-time variation in the critical parameters that control how soil water status influences bare soil evaporation and transpiration is still limited by scarcity of detailed observational data. The few datasets that do exist tend to describe canopy-scale aggregate ET, field-scale ET from lysimetry, or leaf-scale transpiration on individual plants (Baldocchi et al. 2004; Black 1979; Dunin and Greenwood 1986; Federer 1979; Kurc and Small 2004; Mahfouf et al. 1996; Teuling et al. 2006; Williams and Albertson 2004). Aggregating or disaggregating these measures to the scale of functional units such as whole plants, plant functional types, or landscape patches continues to be a challenge, though stable isotopes (e.g., Ferretti et al. 2003; Williams et al. 2004; Yepez et al. 2003) could be very helpful.

The biological mechanisms that cause lagged responses of respiration and productivity are still speculative. While recovery from a desiccated, water-stressed state is qualitatively understood and may even be parameterized experimentally, biochemical and biophysical models have not advanced to the level of refinement needed to characterize such up- or downregulation in a mechanistic way. Similarly, models that contain the detailed soil and plant biogeochemistry needed for characterizing $\mathrm{C}$ pool dynamics (e.g., Century, CASA, or Biome-BGC) are only beginning to be implemented at the daily time scale, and likely still miss the pulse-like responses that characterize water and $\mathrm{C}$ fluxes in intermittently wetted, semi-arid biomes.

Acknowledgments The authors would like to thank Ian McHugh and Walter Kubheka of Kruger National Park, South Africa for field technical support. The fieldwork supporting these findings has been conducted in full compliance with current laws in South Africa. The Skukuza flux tower was supported by grants from the National Aeronautic and Space Administration, the United States National Science Foundation and NOAA, as well as funds from the South African National Research Foundation and Council for Scientific and Industrial Research and the Deutsche Forschungsgemeinschaft (grant Ku 1099/2-1).

\section{References}

Aubinet $\mathrm{M}$ et al (2000) Estimates of the annual net carbon and water exchange of forests: The EUROFLUX methodology. In: Advances in Ecological Research, vol 30, pp 113-175
Austin AT et al (2004) Water pulses and biogeochemical cycles in arid and semiarid ecosystems. Oecologia 141:221-235

Baldocchi D (2003) Assessing the eddy covariance technique for evaluating carbon dioxide exchange rates of ecosystems: past, present and future. Glob Chang Biol 9:479-492

Baldocchi DD, Xu LK, Kiang N (2004) How plant functional-type, weather, seasonal drought, and soil physical properties alter water and energy fluxes of an oak-grass savanna and an annual grassland. Agric For Meteorol 123:13-39

Baldocchi D, Tang J, Xu LK (2006) How switches and lags in biophysical regulators affect spatial-temporal variation of soil respiration in an oak-grass savanna. J Geophys Res 111:G02008. doi:02010.01029/02005JG000063

BassiriRad H, Tremmel DC, Virginia RA, Reynolds JF, de Soyza AG, Brunell MH (1999) Short-term patterns in water and nitrogen acquisition by two desert shrubs following a simulated summer rain. Plant Ecol 145:27-36

Biggs HC, du Toit JT, Rogers KH (2003) The Kruger experience: ecology and management of savanna heterogeneity. Island Press, Washington, DC

Black T (1979) Evapotranspiration from Douglas fir stands exposed to soil water deficits. Water Resour Res 15:164-170

Briggs JM et al (2005) An ecosystem in transition. Causes and consequences of the conversion of mesic grassland to shrubland. Bioscience 55:243-254

Campbell GS, Norman JM (1998) An introduction to environmental biophysics, 2nd edn. Springer, New York

Collins SL et al (2008) Pulse dynamics and microbial processes in aridland ecosystems. J Ecol 96:413-420

Dunin F, Greenwood E (1986) Evaluation of the ventilated chamber for measuring evaporation from a forest. Hydrol Process 1:47-62

Eugster W, Senn W (1995) A cospectral correction model for measurement of turbulent no 2 flux. Bound-Layer Meteorol $74: 321-340$

Falge E et al (2001) Gap filling strategies for long term energy flux data sets. Agric For Meteorol 107:71-77

Falge E et al (2002) Seasonality of ecosystem respiration and gross primary production as derived from FLUXNET measurements. Agric For Meteorol 113:53-74

Federer CA (1979) A soil-plant-atmosphere model for transpiration and availability of soil water. Water Resour Res 15:555-562

Ferretti DF, Pendall E, Morgan JA, Nelson JA, LeCain D, Mosier AR (2003) Partitioning evapotranspiration fluxes from a Colorado grassland using stable isotopes: seasonal variations and ecosystem implications of elevated atmospheric $\mathrm{CO}_{2}$. Plant Soil 254:291-303

Fravolini A, Hultine KR, Brugnoli E, Gazal R, English NB, Williams DG (2005) Precipitation pulse use by an invasive woody legume: the role of soil texture and pulse size. Oecologia 144:618-627

Gash JHC (1986) A note on estimating the effect of a limited fetch on micrometeorological evaporation measurements. Bound-Layer Meteor 35:409-13

Gutierrez JR, Whitford WG (1978) Responses of Chihuahuan Desert herbaceous annuals to rainfall augmentation. J Arid Environ 12:127-139

Hsieh CI, Katul G, Chi T (2000) An approximate analytical model for footprint estimation of scalar fluxes in thermally stratified atmospheric flows. Adv Water Resour 23(7):765-772

Hui DF, Luo YQ, Katul G (2003) Partitioning interannual variability in net ecosystem exchange between climatic variability and functional change. Tree Physiol 23:433-442

Huxman TE et al (2004) Precipitation pulses and carbon fluxes in semiarid and arid ecosystems. Oecologia 141:254-268

Jarvis P et al (2007) Drying and wetting of Mediterranean soils stimulates decomposition and carbon dioxide emission: the "Birch effect". Tree Physiol 27:929-940 
Jenerette GD, Scott RL, Huxman TE (2008) Whole ecosystem metabolic pulses following precipitation events. Funct Ecol 22:924-930

Knapp AK, Smith MD (2001) Variation among biomes in temporal dynamics of aboveground primary production. Science 291:481484

Knapp AK et al (2002) Rainfall variability, carbon cycling, and plant species diversity in a mesic grassland. Science 298:2202-2205

Kurc SA, Small EE (2004) Dynamics of evapotranspiration in semiarid grassland and shrubland ecosystems during the summer monsoon season, central New Mexico. Water Resour Res 40

Kutsch WL et al (2008) Response of carbon fluxes to water relations in a savanna. Biogeosciences 5:1797-1808

Lee X, Massman W, Law B (2004) Handbook of micrometeorology: a guide for surface flux measurement and analysis. Kluwer, London

Mahfouf JF et al (1996) Analysis of transpiration results from the RICE and PILPS workshop. Glob Planet Change 13:73-88

Moncrieff JB et al (1997) A system to measure surface fluxes of momentum, sensible heat, water vapour and carbon dioxide. J Hydrol 189:589-611

Noy-Meir I (1973) Desert ecosystems: environment and producers. Annu Rev Ecol Syst 4:25-44

Ogle K, Reynolds JF (2002) Desert dogma revisited: coupling of stomatal conductance and photosynthesis in the desert shrub, Larrea tridentata. Plant Cell Environ 25:909-921

Ogle K, Reynolds JF (2004) Plant responses to precipitation in desert ecosystems: integrating functional types, pulses, thresholds, and delays. Oecologia 141:282-294

Porporato A, Laio F, Ridolfi L, Rodriguez-Iturbe I (2001) Plants in water-controlled ecosystems: active role in hydrologic processes and response to water stress. III. Vegetation water stress. Adv Water Resour 24:725-744

Priestley CHB, Taylor RJ (1972) On the assessment of surface heat flux and evaporation using large-scale parameters. Mon Weather Rev 100:81-92

Reichstein $\mathrm{M}$ et al (2002) Severe drought effects on ecosystem $\mathrm{CO}_{2}$ and $\mathrm{H}_{2} \mathrm{O}$ fluxes at three Mediterranean evergreen sites: revision of current hypotheses? Glob Change Biol 8:999-1017

Reynolds JF, Kemp PR, Ogle K, Fernandez RJ (2004) Modifying the 'pulse-reserve' paradigm for deserts of North America: precipitation pulses, soil water, and plant responses. Oecologia 141:194-210

Rodriguez-Iturbe I, Porporato A, Ridolfi L, Isham V, Cox DR (1999) Probabilistic modelling of water balance at a point: the role of climate, soil and vegetation. Proc R Soc Lond Ser A Math Phys Eng Sci 455:3789-3805

Sala OE, Lauenroth WK (1982) Small rainfall events: an ecological role in semi-arid regions. Oecologia 53:301-304

Sankaran M, Ratnam J, Hanan NP (2004) Tree-grass coexistence in savannas revisited: insights from an examination of assumptions and mechanisms invoked in existing models. Ecol Lett 7:480-490

Scanlon TM, Albertson JD (2004) Canopy scale measurements of $\mathrm{CO}_{2}$ and water vapor exchange along a precipitation gradient in southern Africa. Glob Change Biol 10:329-341

Scholes RJ, Walker BH (1993) An African savanna: synthesis of the Nylsvley study. Cambridge University Press, New York
Scholes RJ et al (1999) The environment and vegetation of the flux measurement site near Skukuza, Kruger National Park. Koedoe 44:73-83

Schwinning S, Sala OE (2004) Hierarchy of responses to resource pulses in and semi-arid ecosystems. Oecologia 141:211-220

Schwinning S, Starr BI, Ehleringer JR (2003) Dominant cold desert plants do not partition warm season precipitation by event size. Oecologia 136:252-260

Schwinning S, Sala OE, Loik ME, Ehleringer JR (2004) Thresholds, memory, and seasonality: understanding pulse dynamics in arid/ semi-arid ecosystems. Oecologia 141:191-193

Slaymaker 0, Spencer T (1998) Physical Geography and Global Environmental Change. Adison Wesley Longman, Harlow

Su HB, Schmid HP, Grimmond CSB, Vogel CS, Oliphant AJ (2004) Spectral characteristics and correction of long-term eddycovariance measurements over two mixed hardwood forests in non-flat terrain. Bound-Layer Meteorol 110:213-253

Tang JW, Baldocchi DD (2005) Spatial-temporal variation in soil respiration in an oak-grass savanna ecosystem in California and its partitioning into autotrophic and heterotrophic components. Biogeochemistry 73:183-207

Tang JW, Baldocchi DD, Xu L (2005) Tree photosynthesis modulates soil respiration on a diurnal time scale. Glob Change Biol 11:1298-1304

Teuling AJ, Seneviratne SI, Williams C, Troch PA (2006) Observed timescales of evapotranspiration response to soil moisture. Geophys Res Lett 33(23), L23403

Verhoef A, Allen SJ, DeBruin HAR, Jacobs CMJ, Heusinkveld BG (1996) Fluxes of carbon dioxide and water vapour from a Sahelian savanna. Agric For Meteorol 80:231-248

Webb W, Szarek S, Lauenroth W, Kinerson R, Smith M (1978) Primary productivity and water-use in native forest, grassland, and desert ecosystems. Ecology 59:1239-1247

Wilczak JM, Oncley SP, Stage SA (2001) Sonic anemometer tilt correction algorithms. Bound-Layer Meteorol 99:127-150

Williams CA, Albertson JD (2004) Soil moisture controls on canopyscale water and carbon fluxes in an African savanna. Water Resour Res 40:1-14

Williams CA, Albertson JD (2005) Contrasting short- and long-time scale effects of vegetation dynamics on water and carbon fluxes in water-limited ecosystems. Water Resour Res 41:W06005 doi: 10.1029/2004WR003750

Williams DG et al (2004) Evapotranspiration components determined by stable isotope, sap flow and eddy covariance techniques. Agric For Meteorol 125:241-258

$\mathrm{Xu}$ LK, Baldocchi DD (2004) Seasonal variation in carbon dioxide exchange over a Mediterranean annual grassland in California. Agric For Meteorol 123:79-96

Xu LK, Baldocchi DD, Tang JW (2004) How soil moisture, rain pulses, and growth alter the response of ecosystem respiration to temperature. Global Biogeochem Cycles 18(4):GB4002

Yepez EA, Williams DG, Scott RL, Lin GH (2003) Partitioning overstory and understory evapotranspiration in a semiarid savanna woodland from the isotopic composition of water vapor. Agric For Meteorol 119:53-68 